\section{PATRIMONIALIZAÇÃO, CASA BRANCA E RESISTÊNCIA NEGRA: SOBRE AS RESSIGNIFICAÇÕES DO INSTITUTO DO TOMBAMENTO}

\author{
PATRIMONIALIZATION, TERREIRO CASA BRANCA, AND \\ BLACK RESISTANCE: ABOUT THE RESIGNIFICATIONS OF \\ THE HERITAGE LISTING PROCESS
}

RVD

Recebido em

23.04.2020

Aprovado em

22.05.2020

Paulo Fernando Soares Pereira ${ }^{1,2}$

\title{
RESUMO
}

O artigo objetiva discutir como a patrimonialização do Terreiro Casa Branca e a sua negra resistência contribuiu para ressignificar 0 instituto do tombamento, dando abertura para dessacralizá-lo. Considerando o instituto como o mais tradicional instrumento do Direito Administrativo a serviço da proteção de bens culturais no Brasil, o tombamento tem sua história marcada pela transplantação de um modelo português, o qual, não raras vezes, foi utilizado como discurso para negar proteção a bens culturais que denotam nítido caráter de brasilidade. A metodologia utilizada foi a revisão crítica de literatura e análise do processo de tombamento do Terreiro Casa Branca. Como conclusão, demonstra-se que o Direito está relacionado às questões de poder, inclusive às raciais, sendo necessário tomar-se consciência dessa relação, a fim de não se criarem bloqueios aos patrimônios dos sujeitos subalternizados.

PALAVRAS-CHAVE: Tombamento; Ressignificação; Novos patrimônios; Quilombos.

\section{ABSTRACT}

The article discusses how the patrimonialization of the Terreiro Casa Branca and its black resistance contributed to give a new meaning to the process of listing heritage, giving an opening to "desanctify" it. Considering the process as the most traditional procedure of

\footnotetext{
1 Doutor em Direito, Estado e Constituição pela Universidade de Brasília - UnB. Mestre em Direito e Instituições de Justiça pela Universidade Federal do Maranhão - UFMA. Graduado em Direito pela Universidade Federal de Roraima - UFRR. Integrante da Advocacia-Geral da União (Procurador Federal, atuando em demandas relacionadas aos povos indígenas, comunidades quilombolas e patrimônio cultural brasileiro). E-mail: paulofsp1983@gmail.com. ORCID: http://orcid.org/0000-0001-6802-9035

2 Endereço do autor: Av. Monção, Quadra 35, Lote 01, S/N. Loteamento Boa Vista Edifício Via Manhattan Center III, Jardim Renascença, CEP 65075-692 São Luís/MA Telefone: (98) 2109- 7841.
} 
Administrative Law in the field of the protection of cultural assets in Brazil, the listing process has in its history examples of the use of a Portuguese model, which, often, was used as a political discourse to deny the protection to property and cultural assets that denote clear Brazilian characteristics. The methodology used was the review and analysis of the Terreiro Casa Branca listing process. In conclusion, we demonstrate that the Law is related to matters of power, including racial ones, being necessary to become aware of it, in order not to block the protection of cultural assets of secondary groups.

KEYWORDS: Listing process; Resignification; New assets; Quilombos.

\section{INTRODUÇÃO}

O tombamento ${ }^{3}$ é o mais tradicional instrumento do Direito Administrativo a serviço da proteção de bens culturais no Brasil e tem sua história marcada pela transplantação de um modelo português, o qual, não raras vezes, foi utilizado como discurso para negar proteção a bens culturais que denotam nítido caráter de brasilidade.

Nesse contexto, o artigo objetiva discutir como a patrimonialização do Terreiro Casa Branca e a sua negra resistência contribuiu para ressignificar o instituto do tombamento, dando abertura para dessacralizá-lo.

A problemática, portanto, a ser discutida está em analisar como a redução da patrimonialidade brasileira ao repertório de bens de excepcional valor, traduzida pela exclusividade do tombamento, revela o caráter político da seleção de nosso legado cultural.

Esse legado possui um histórico de privilégio às expressões culturais de uma determinada classe ou grupo social como a de tradição europeia, herança luso-colonial geralmente identificada com o poder constituído, pois a noção de patrimônio e a política

3 Para Márcia Chuva (2009, p. 189), quem sugeriu a utilização do termo tombamento foi Mário de Andrade, em seu anteprojeto incorporado no Decreto-Lei n 25/37, distinguindo-se da terminologia aplicada na legislação francesa, apesar dos princípios de ambos serem semelhantes. Outras discussões envolvendo o uso da terminologia no Brasil e em Portugal, cf. PEREIRA, Julia Wagner. O tombamento: de instrumento a processo na construção de uma ideia de Nação. In: CHUVA, Márcia; NOGUEIRA, Antonio G. Ramos. Patrimônio cultural: políticas e perspectivas de preservação no Brasil. Rio de Janeiro: Mauad - FAPERJ, 2012c, p. 159-170. 
oficial de preservação revelaram-se elitistas e conservadoras ${ }^{4}$, principalmente num país caracterizado pela contradição e pluralidade étnico-cultural, em que gama enorme de bens significativos não foi preservada por não se encaixar nessa categorização engessada de patrimônio, deixando-se de fora ou foram destruídos ou relegados ao esquecimento como as senzalas, os quilombos e os terreiros, as primeiras fábricas, os cortiços e as vilas operárias (NOGUEIRA, 2008, p. 241).

Como conclusão, demonstra-se que o Direito está relacionado às questões de poder, inclusive às raciais, sendo necessário tomar-se consciência dessa relação, a fim de não se criarem bloqueios aos patrimônios dos sujeitos subalternizados. A inadequação ou não do instituto do tombamento para os novos patrimônios parece ser muito mais uma invenção decorrente das relações de poder que se firmaram no âmbito do patrimônio do que propriamente uma questão jurídica.

A metodologia utilizada foi a revisão crítica de literatura e análise do processo de tombamento do Terreiro Casa Branca. Por fim, sistematizou-se a organização do artigo com o seguintes tópicos: a) A patrimonialização e a obsessão pelo tombamento; b) Casa Branca, resistência negra e patrimonialização; c) A ampliação dos instrumentos de proteção dos direitos culturais; d) Patrimonialização antirracista e o reconhecimento de patrimônios insurgentes e; e) Novas possibilidades interpretativas a respeito do tombamento a partir da Constituição de 1988.

\section{A PATRIMONIALIZAÇÃO E A OBSESSÃO PELO TOMBAMENTO}

Se se pode afirmar que a noção de patrimônio se tornou maleável e ampla, capaz de agregar valores, visões de mundo e ações políticas nem sempre harmoniosas

\footnotetext{
${ }^{4}$ A respeito da concepção de patrimônio que se formou no Brasil, cf. CHUVA, Márcia; NOGUEIRA, Antonio Gilberto Ramos. Patrimônio cultural: políticas e perspectivas de preservação no Brasil. Rio de Janeiro: Mauad, 2012c; COSTA, Everaldo Batista da. Cidades da patrimonizalização global: simultaneidade totalidade urbana - totalidade-mundo. São Paulo: Humanitas, 2015; GONÇALVES, José Reginaldo Santos. Autenticidade, memória e ideologias nacionais: o problema dos patrimônios culturais. Estudos Históricos, vol. 1, nํ2, p. 264-275, 1988; MARTINS, Clerton. Patrimônio cultural: da memória ao sentido do lugar. São Paulo: Roca, 2006; PAULA, Zuleide Casagrande de; MENDONÇA, Lúcia Glicério; ROMANELLO, Jorge Luís. Polifonia do patrimônio. Londrina: EDUEL, 2012.
} 
ou coerentes entre si ${ }^{5}$ (CHUVA, 2012b, p. 152). Por sua vez, a proteção jurídica do patrimônio cultural brasileiro, apesar de, hoje, dispor de vários de instrumentos, ainda permeia-se pelas concepções relacionadas ao instituto do tombamento e dos essencialismos.

Até agora, a teoria administrativa não apresentou relevantes discussões que inovassem ou se adequassem o instituto às complexas relações sociais que envolvem a patrimonialização. Nesse sentido, a proteção no bojo do tombamento, e a estruturação da burocracia patrimonial nascem juntas, daí a obsessão em torno do instituto. Márcia Sant'anna (2015, p. 16), lembra que,

A criação do IPHAN em 1937 é, sem dúvida, o principal marco da institucionalização das ações de preservação no Brasil. Um elemento definidor do longo período, que vai desse ano até a década de 1960, não seria, contudo, a ação institucional, mas o que se pode chamar de processo de conquista, nos tribunais da constitucionalidade, da proteção legal ao patrimônio com base no instituto do tombamento criado pelo Decreto-lei $n^{\circ} 25$, de 30 de novembro de 1937. A despeito dos inúmeros e importantes acontecimentos que marcaram esse período, a proteção legal constituiu, certamente, a ação de preservação dominante e catalisadora de energias. A conquista da constitucionalidade do ato de limitar o uso, gozo e fruição da propriedade privada e a definição das normas para a implementação desse ato mobilizaram a ação institucional, tanto quanto a seleção do que preservar.

Dos institutos que regem a questão patrimonial brasileira, o tombamento se destaca. Sua primogenitura e antiguidade em relação aos demais institutos, em vista da impressão de que o próprio instituto foi "tombado" da forma mais rigorosa possível como uma espécie de sacralização ou de construção de dogma religioso, diante das dificuldades de uso quando surgem novas formas de patrimonialização, principalmente

\footnotetext{
${ }^{5}$ Sobre gestão de políticas patrimoniais no Brasil, cf. CALABRE, Lia. Políticas culturais no Brasil: dos anos 1930 ao século XXI. Rio de Janeiro: FGV, 2009; CHUVA, Márcia Regina Romeiro. Os arquitetos da memória: sociogênese das práticas de preservação do patrimônio cultural no Brasil (anos 19301940). Rio de Janeiro: EDUFRJ, 2009; CHUVA, Márcia. Preservação do patrimônio cultural no Brasil: uma perspectiva histórica, ética e política. In: CHUVA, Márcia; NOGUEIRA, Antonio Gilberto Ramos. Patrimônio cultural: políticas e perspectivas de preservação no Brasil. Rio de Janeiro: Mauad, 2012, p. 67-78; FUNARI, Pedro Paulo Abreu; PELEGRINI, Sandra de Cássia Araújo. Patrimônio histórico e cultural. Rio de Janeiro: Zahar, 2006.
} 
aquelas que suscitam a proteção de patrimônios dissidentes ou subalternizados, como os indígenas e afro-brasileiros.

Sobre isso, Flávio de Lemos Carsalade (2011, p. 5) argumenta que ao mudar a cultura, transformam-se os valores e mudam-se as atitudes em relação ao patrimônio e o que se preserva, em verdade, é a identidade em transformação, ou seja, a preservação não está na capacidade do bem de permanecer como está, mas na sua capacidade de mudar junto com as mudanças socioculturais. Assim, tal concepção se choca com a acepção de imutabilidade do bem a ser preservado, pois também ele, como a tradição e a cultura, está em constante transformação (CARSALADE, 2011, p. $5)$.

Não é pretensão deste trabalho fazer uma arqueologia do tombamento. Porém, quer-se apenas explicar que o instituto tem apresentado pouca evolução se comparado com as novas perspectivas que a questão patrimonial revela. Pode-se definir o tombamento como ato do Poder Público que, reconhecendo o valor cultural (histórico, arqueológico, etnográfico, artístico ou paisagístico) de um bem, mediante sua inscrição em livro próprio, subordina-o ao regime especial que the impõe vínculos de destinação, de não modificação ou de relativa inalienabilidade (SILVA, 2001), ou, ainda, como um instrumento da ação administrativa do Estado destinado a proteger bens revestidos de valor cultural, podendo ser definido por sua finalidade, pois está circunscrito, em qualquer hipótese, ao atendimento de um interesse público de natureza determinada: a defesa e a preservação de bens culturais (ZANDONADE, 2012).

Dessa forma, em regra, os livros os quais discutem o tombamento costumam pautar as suas discussões de forma bastante tradicional, limitando-se a apresentar algumas inovações que, vez ou outra, são ofertadas pela atividade jurisprudencial ${ }^{6}$.

\footnotetext{
${ }^{6}$ Além das concepções manualescas, cf. BRAGA, Robério dos S. P. 0 instituto do tombamento e proteção do bem cultural. Manaus: EDUEA, 2007; CUNHA FILHO, Francisco Humberto (org.). Proteção do patrimônio cultural brasileiro por meio do tombamento: estudo crítico e comparado das legislações estaduais organizada por regiões. Fortaleza: EDUFC, 2013; COSTA, Rodrigo V. A dimensão constitucional do patrimônio cultural: o tombamento e o registro sob a ótica dos direitos culturais. Rio de Janeiro: Lumen Juris: 2011; FEITOZA, Paulo Fernando de B. Patrimônio cultural: proteção e responsabilidade objetiva. Manaus: Valer, 2012; MARCHESAN, Ana Maria Moreira. A tutela do patrimônio cultural sob o enfoque do direito ambiental. Porto Alegre: Livraria do Advogado, 2007;
} 
Apesar disso, saliente-se que o instituto, em Portugal, país de onde se copiou o modelo, a ideia de tombamento tem sentido mais abrangente. Lá, não se utiliza sequer a expressão "tombamento", mas, sim, a terminologia de "classificação"7, dada pela Lei no 107/2001, ao estabelecer, no art. 18, que

1 - Entende-se por classificação o acto final do procedimento administrativo mediante o qual se determina que certo bem possui um inestimável valor cultural.

2 - Os bens móveis pertencentes a particulares só podem ser classificados como de interesse nacional quando a sua degradação ou o seu extravio constituam perda irreparável para o património cultural.

3 - Dos bens móveis pertencentes a particulares só são passíveis de classificação como de interesse público os que sejam de elevado apreço e cuja exportação definitiva do território nacional possa constituir dano grave para o património cultural.

4 - Só é possível a classificação de bens móveis de interesse municipal com o consentimento dos respectivos proprietários.

Ainda assim, é consensual se mencionar o tombamento como originário do Direito português, sem se questionar a maneira como ele é utilizado naquele país. Portanto, registre-se que, durante muito tempo, o tombamento, ao mesmo tempo que protegia os patrimônios que recebiam a distinção do Estado, dava suporte ao conservadorismo patrimonial brasileiro, o qual fazia uso, como ato dissimulado, para não reconhecer os patrimônios dissidentes, tendo sido usado como argumento de autoridade de instituto jurídico para deslegitimar as pretensões dos novos patrimônios,

MOURÃO, Henrique A. Patrimônio cultural como um bem difuso: o direito ambiental e a defesa dos interesses coletivos por organizações não governamentais. Belo Horizonte: Del Rey, 2009; PEREIRA, Paulo Fernando Soares. O direito ao desenvolvimento cultural e as políticas de proteção ao patrimônio cultural. Rio de Janeiro: Lumen Juris, 2015; RABELLO, Sonia. O Estado na preservação de bens culturais: o tombamento. Rio de Janeiro: IPHAN, 2009; RODRIGUES, Francisco Luciano L. Patrimônio cultural: a propriedade dos bens culturais no Estado Democrático de Direito. Fortaleza: EDUNIFOR, 2008; RODRIGUES, José Eduardo R.; MIRANDA, Marcos P. de S. Estudos de direito do patrimônio cultural. Belo Horizonte: Fórum, 2012; SILVA, Fernando Fernandes da. As cidades brasileiras e o patrimônio cultural da humanidade. São Paulo: Peirópolis - EDUSP, 2012; SILVA, José Afonso da. Ordenação constitucional da cultura. São Paulo: Malheiros, 2001; SOARES, Inês V. Prado. Direito ao (do) patrimônio cultural brasileiro. Belo Horizonte: Fórum, 2009; ZANDONADE, Adriana. O tombamento à luz da Constituição Federal de 1988. São Paulo: Malheiros, 2012.

7 A respeito do processo de classificação em Portugal, cf. BRITO, Miguel N. de. O procedimento de classificação de bens culturais. In: GOMES, Carla A.; RAMOS, José L. Bonifácio. Direito da cultura e do património cultural. Lisboa: AAFDL, 2011, p. 418-436; GOMES, Carla A. Textos dispersos de direito do património cultural e de direito urbanístico. Lisboa: AAFDL, 2008. 
como ocorreu com o Terreiro da Casa Branca do Engenho Velho, Sociedade São Jorge do Engenho Velho ou llê Axé lyá Nassô Oká, onde, inicialmente, o argumento invocado era no sentido de que "não se poderia efetuar o tombamento de uma religião", dado o caráter "limitado" do instituto.

Desse modo, o uso do tombamento para a proteção de um terreiro de candomblé serviu para demonstrar que o instituto é mais maleável do que se pensa, estando sujeito às relações de poder vigentes e o discurso negador geralmente se vale de uma suposta inadequação do instituto para a proteção dos novos patrimônios, como forma de fortalecer apenas patrimonialidades tradicionais.

\section{CASA BRANCA, RESISTÊNCIA NEGRA E PATRIMONIALIZAÇÃO}

O tombamento do Terreiro Casa Branca do Engenho Velho ${ }^{8}$, na cidade de Salvador, no Estado da Bahia, tem uma importância significativa para as relações entre o Estado brasileiro e a luta pelo reconhecimento das identidades não hegemônicas. Foi a primeira vez ${ }^{9}$, no âmbito de políticas patrimoniais, que a tradição afro-brasileira obteve o reconhecimento oficial do Estado Nacional, sendo que, à época, vários membros do Conselho Consultivo do Serviço de Patrimônio Histórico e Artístico Nacional - SPHAN consideravam desproposital e equivocado tombar um pedaço de terra desprovido de construções que justificassem, por sua monumentalidade ou valor artístico, tal iniciativa e, até aquele período, o instituto jurídico do tombamento vinha sendo aplicado, basicamente, a edificações religiosas, militares e civis da tradição luso-brasileira (VELHO, 2006, p. 237).

\footnotetext{
8 Inscrições no 93 (Livro Arqueológico, Etnográfico e Paisagístico) e no 504 (Livro Histórico), em 14/08/86. 9 O "Acervo do Museu da Magia Negra", tombado em 1938 (processo 35-T-1938), com registro no Livro do Tombo Arqueológico Etnográfico e Paisagístico (Inscrição no 1 de 05/05/1938) em que pese a sua relevância, foi tombado em um contexto no qual imperava a negatividade sobre os cultos afrobrasileiros, tanto que tais objetos sagrados, até hoje, permanecem, "sob guarda", para não se dizer "aprisionados", do Museu da Polícia Civil do Rio de Janeiro, inclusive, há bastante tempo sem exposição ao público, demonstrando-se que as práticas estatais ainda são permeadas pelos racismo institucional, cultural e religioso. Negar exposição a esse acervo sob o argumento de falta de recursos para manutenção/restauração/exposição etc. é uma forma de "não decisão" que afeta a sacralidade do acervo, constituindo-se forma de racismo religioso forjada pelo Estado e seus agentes.
} 
https://doi.org/10.20873/uft.2359-0106.2020.v7n2.p1-27

O terreiro de Casa Branca apresentava uma tradição de mais de 150 anos e, com certeza, desempenhava um importante papel na simbologia e no imaginário dos grupos ligados ao mundo do candomblé e aos cultos afro-brasileiros em geral. Do ponto de vista dessas pessoas o que importava era a sacralidade do terreno, o seu "axé". Em termos de cultura material, encontrava-se um barco, importante nos rituais, um modesto casario, além da presença de arvoredo e pedras associados ao culto dos orixás. Não era nada que pudesse se assemelhar à Igreja de São Francisco em Ouro Preto, aos profetas de Aleijadinho em Congonhas, em Minas Gerais, ao Mosteiro de São Bento, ao Paço Imperial da Quinta da Boa Vista ou à Fortaleza de Santa Cruz, no Rio de Janeiro. Tratava-se, sem dúvida, de uma situação inédita e desafiante (VELHO, 2006, p. 237-238).

Sobre a controvérsia que contorna as noções de patrimônio vigentes à época do tombamento da Casa Branca do Engenho Velho, Gilberto Velho, relator do processo junto ao Conselho Consultivo do Serviço de Patrimônio Histórico e Artístico Nacional SPHAN (atual IPHAN), escreveu:

O caso do tombamento de Casa Branca poderia ser analisado como um drama social nos termos de Victor Turner (1974). Havia um grupo de atores bem definido com opiniões e mesmo interesses não só diferenciados mas antagônicos em torno de uma temática que se revelava emblemática para a própria discussão da identidade nacional. Independentemente de aspectos técnicos e legais, o que estava em jogo era, de fato, a simbologia associada ao Estado em suas relações com a sociedade civil. Tratava-se de decidir o que poderia ser valorizado e consagrado através da política de tombamento. Reconhecendo a válida preocupação de conselheiros com a justa implementação da figura do tombamento, hoje é impossível negar que, com maior ou menor consciência, estava em discussão a própria identidade da Nação brasileira.

A rápida passagem do Cardeal Primaz na histórica reunião não disfarçava que os setores mais conservadores do catolicismo baiano e, mesmo nacional viam com maus olhos a valorização dos cultos afrobrasileiros.

Quando conselheiros argumentavam que não se podia "tombar uma religião", certamente entendiam que o tombamento de centenas de igrejas e monumentos católicos teria se dado apenas por razões artístico-arquitetônicas, o que não nos parecia correto. Assim, o tombamento de Casa Branca significava a afirmação de uma visão da sociedade brasileira como multiétnica, constituída e caracterizada pelo pluralismo sociocultural. Não há dúvida de que tal medida de reconhecimento do Estado representava também uma reparação às perseguições e à intolerância manifestadas durante séculos pelas elites 
e pelas autoridades brasileiras contra as crenças e os rituais afrobrasileiros (VELHO, 2006, p. 240).

Nota-se o tombamento da Casa Branca como significativo para a proteção do patrimônio cultural brasileiro, pois houve rompimento de um paradigma de proteção cultural que se voltava apenas à tradição luso-brasileira ${ }^{10}$. Nesse episódio, a cidade de Salvador foi o local de um embate que repercutiu e atingiu toda a sociedade nacional e após o reconhecimento do patrimônio de "outros sujeitos", não só outros terreiros foram tombados, como a Casa das Minas ${ }^{11}$, em São Luís, Estado do Maranhão, mas diversos monumentos e construções ligadas a outras tradições que não a luso-brasileira foram igualmente reconhecidas, a exemplo de uma residência de colono, no Rio Grande do Sul, uma casa de chá japonesa, em São Paulo e, posteriormente, com base na valorização da cultura imaterial, rituais indígenas como o Quarup (VELHO, 2006, p. 240).

O principal aspecto jurídico desse processo fundava-se no entendimento segundo o qual era preciso proteger o terreiro. Discordava-se, porém, do uso do tombamento, o que fez tal discussão não se restringir à burocracia do Conselho Consultivo do SPHAN, aspecto irradiado por Salvador e pelo Brasil; a vitória pelo

\footnotetext{
10 O uso da expressão "romper paradigma" vai no sentido expresso por Thomas S. Kuhn (1995, p. 114), segundo o qual as mudanças de paradigmas promovem alterações significativas nos critérios que determinam a legitimidade, tanto dos problemas, como das soluções propostas.

${ }^{11} \mathrm{O}$ tombamento da Casa das Minas, em 2002 (Processo no 1464-T-00), tem importância porque se trata de uma casa de tradição Mina-Jeje, a qual difere de boa parcela dos cultos afro-brasileiros de matriz Nagô, a exemplo do Terreiro Casa Branca, cf. CARNEIRO, Deusdédit. O tombamento da Casa das Minas. Boletim on-line da Comissão Maranhense de Folclore, no 18, p. 1-2, jan. 2001b; CAVALCANTI, Maria Laura Viveiros de Castro. A Casa das Minas de São Luís do Maranhão e a saga de Nã Agontimé. Sociologia \& Antropologia, vol. 9, oㅡ 02, p. 387-429, maio/ago. 2019; FERRETTI, Mundicarmo. Encantaria maranhense: um encontro do negro, do índio e do branco na cultura afro-brasileira. Boletim on-line da Comissão Maranhense de Folclore, no 18, p. 7-9, jan. 2001; FERRETI, Sérgio F. Casa das Minas - religião popular e mudança. Revista do Patrimônio, no 25, p. 38-42, 1997; FERRETTI, Sérgio F. Beija-flor e a Casa das Minas. Boletim on-line da Comissão Maranhense de Folclore, no 18, p. 9-10, jan. 2001; FERRETTI, Sergio F. Tombamento da Casa das Minas. Boletim on-line da Comissão Maranhense de Folclore, № 24, p. 3, dez. 2002; FERRETTI, Sergio F. Querebentã de Zomadônu: etnografia da Casa das Minas do Maranhão. São Paulo: Pallas, 2009; LEAL, João. Religião como cultura? As festas do Divino, o Tambor de Mina e o regime patrimonial. Revista Pós Ciências Sociais, vol. 15, no 30, p. 91-112, jul./dez. 2018; PEREIRA, Nunes. A Casa das Minas: contribuição ao estudo das sobrevivências daomeianas no Brasil. Rio de Janeiro: SBAE, 1947; VERGER, Pierre. Uma rainha africana mãe de santo em São Luís. Revista USP, p. 152-158, jun./ago. 1990.
} 
tombamento não foi fácil e teve forte mobilização da sociedade civil disputando a narrativa em torno do direito de dizer o que poderia ser patrimonializado ou reconhecido como identidade nacional (VELHO, 2006, p. 239).

Parte das discussões em torno do tombamento do Terreiro da Casa Branca usava, exatamente, a juridicidade do instituto para bloquear parcela da patrimonialidade brasileira, ou seja, para que não fosse reconhecida pelo Estado. Márcia Sant'anna (2015, p. 17), ao tratar dessa limitação do instituto jurídico, previsto no Decreto no 25/37, diante da amplitude do patrimônio cultural brasileiro, comenta que:

O objeto da preservação é referido, ao longo de todo o texto desse decreto, como "coisa tombada", pois o tombamento - como o instrumento da legislação francesa de 1913, no qual ele também se baseia - não foi codificado legalmente para proteger ou preservar manifestações de outra natureza que não a estritamente material, e seus efeitos dirigem-se, exclusivamente, à proteção de bens individualizados e de conjuntos finitos e individualizáveis de bens. Assim, o "folclore ameríndio", composto por "vocabulários, cantos, lendas, magias, medicina, culinária", e o "folclore popular" com sua música, "cantos, histórias, lendas, superstições, medicina, receitas culinárias, provérbios, ditos, danças dramáticas", referidos como patrimônio no anteprojeto de Mário de Andrade para o Serviço do Patrimônio Artístico Nacional (BRASIL, 1980, p. 90-106), não são enquadráveis nesses parâmetros e não encontraram lugar no rol do patrimônio então constituído (SANT'ANNA, 2015, p. 17).

Márcia Sant'anna (2015, p. 32-33), também, argumenta que é necessário reconhecer que não faz sentido a permanência no Brasil de um sistema de preservação do patrimônio ancorado principalmente no instituto do tombamento, como vem sendo feito há quase 80 (oitenta) anos, sendo urgente a complementação desse instrumento, o que inclui pensar em mecanismos que reflitam uma concepção ampliada de patrimônio cultural, assim como estudar e refletir mais sobre a possibilidade de adaptação, à nossa realidade, de sistemas de preservação mais abrangentes, integrados e articulados ao planejamento e à política urbana, a exemplo dos que existem em países como França, Itália, Inglaterra e Estados Unidos. 


\section{A AMPLIAÇÃO DOS INSTRUMENTOS DE PROTEÇÃO DOS DIREITOS CULTURAIS}

Sabedores ou não dessas limitações, os constituintes da Constituição Federal de 1988 romperam com o monopólio do tombamento como principal instituto jurídico capaz de tutelar o patrimônio cultural brasileiro, ao estabelecer, no $\S 1^{\circ}$ do art. 216, que "o Poder Público, com a colaboração da comunidade, promoverá e protegerá o patrimônio cultural brasileiro, por meio de inventários, registros, vigilância, tombamento e desapropriação, e de outras formas de acautelamento e preservação".

Não se desmerece o instituto, contudo, atualmente, as interpretações que se referem ao tombamento devem ser capazes de adequá-lo às novas necessidades que o patrimônio cultural brasileiro invoca, como foi demonstrado no próprio exemplo de tombamento do Terreiro Casa Branca. Do ponto de vista jurídico, esse foi o primeiro caso no qual se possibilitou ressignificar/ressemantizar o instituto do tombamento, daí a sua importância nesta discussão.

Em verdade, a prática da instituição do patrimônio cultural tem sido um ato dominado apenas pela lógica estatal, onde o tombamento, como instituinte do valor cultural, credenciava a inclusão do bem em um rol formalmente definido e, com a Constituição de 1988, reconheceu-se aquilo que é posição corrente, há bastante tempo, nas Ciências Sociais, segundo o qual os valores culturais não são criados pelo Estado, mas pela sociedade (MENESES, 2012, p. 33), assim como a noção de bens culturais que esteva vinculada à noção de bens patrimoniais (no sentido de propriedade, edificação) migra para a noção de referências culturais, assumidamente relacionada com a noção antropológica de cultura (LIMA FILHO, 2009, p. 618).

A Constituição Federal de 1988, a partir das experiências de tombamento do Terreiro Casa Branca e da Serra da Barriga (antigo Quilombo dos Palmares), ampliou a noção de patrimônio buscando abarcar a produção dos esquecidos e reforçando seu valor cultural; situado num movimento maior de revisão da historiografia e que, no Brasil, coincide com o surgimento dos movimentos sociais no processo de 
redemocratização, o conceito de patrimônio cultural colocou no centro do debate outros atores que não os burocratas e intelectuais ${ }^{12}$; nesse sentido, o patrimônio passou a ser visto não apenas como remanescente de uma memória histórica, informadora de uma identidade nacional que pouco diz à maioria da população, mas como importante testemunho das temporalidades que compõem as múltiplas experiências vividas, individual ou coletivamente; portanto, campo privilegiado na reelaboração das novas identidades coletivas e instrumento fundamental para o reconhecimento dos grupos sociais que as constroem (NOGUEIRA, 2008, p. 242).

Nesse seguimento, a escassez de referências às matrizes africanas e indígenas no conjunto do patrimônio cultural era explicada pela suposta ausência de testemunhos materiais dessas populações e pela tendência em valorizar as edificações representativas das formas estéticas e arquitetônicas europeias; a existência de apenas um instrumento jurídico, o tombamento, e o foco na materialidade do patrimônio também contribuíram para que vestígios materiais vinculados ao universo cultural indígena e negro não fossem valorizados a ponto de fazerem parte do conjunto de bens culturais; a maior parte da trajetória da política de preservação no Brasil esteve relacionada, portanto, à manutenção de bens culturais representativos de uma elite cultural e social que construíram ${ }^{13}$, por meio dos discursos intelectual e técnico, um retrato da Nação a partir de um conjunto específico de bens culturais (LIMA, 2014, p. 5$6)$.

Sendo assim, quando se discute o tombamento quilombola, por exemplo, previsto no art. 216, § 5을 da Constituição Federal, há necessidade de compreensão a respeito dos novos usos do patrimônio, o que, sem dúvidas, afeta a própria ideia de

\footnotetext{
12 Sobre o papel dos intelectuais e a construção do patrimônio no Brasil, cf. CHUVA, Márcia Regina Romeiro. Os arquitetos da memória: sociogênese das práticas de preservação do patrimônio cultural no Brasil (anos 1930-1940). Rio de Janeiro: EDUFRJ, 2009, p. 91-142; VELOSO, Mariza. O tecido do tempo: o patrimônio cultural no Brasil e a Academia SPHAN, a relação entre o moderno e o barroco. Brasília: EDUnB, 2017.

${ }^{13}$ A respeito da gestão cultural no Brasil, cf. COELHO, Teixeira. A cultura e seu contrário: cultura, arte e política pós-2001. São Paulo: lluminuras/Itaú Cultural, 2008; DURAND, José Carlos. Política cultural e economia da cultura. Cotia/São Paulo: Ateliê Editorial/Edições SESC, 2013.
} 
"tombamento", não mais como um mero marcador de referências passadas, mas das identidades presentes.

O tombamento quilombola não é algo pronto. Sua formatura, desde que não implique em redução de direitos para as comunidades quilombolas ou mero entretenimento e demonstração de exotismo para as classes dominantes ${ }^{14}$, pressupõe a formulação de uma nova espécie de tombamento, adequada às necessidades culturais das comunidades quilombolas, no caso, e afirmação da resistência negra, em sua predominância, à opressão da escravidão (PEREIRA, 2019; 2020). Não se trata de mera repetição de um instituto jurídico no texto constitucional. Trata-se de abertura constitucional para se reformular o instituto, ressignificando às necessidades das comunidades quilombolas, o que só poderá ser feito caso elas sejam partícipes da formulação de uma política patrimonial voltada para os seus intereses (PEREIRA, 2019; 2020).

O tombamento quilombola, a abranger "todos os documentos e sítios", é uma oportunidade que a Constituição Federal confere para se construir nova noção de proteção jurídica de um patrimônio dissidente/resistente, a qual requer a participação da sociedade, representada principalmente pelos quilombolas, como principais sujeitos interessados, na construção desse novo paradigma. Como é um tombamento que envolve direitos das comunidades "tradicionais", deve ser formulado a se evitar a "frigorificação" de suas identidades ou focado em essencialismos que castram a dinamicidade, a contemporaneidade e a complexidade das comunidades quilombolas, em fenômeno que Rita Laura Segato (2005) denominou de "enlatamento" das identidades e essencialismos caricatos:

\footnotetext{
${ }^{14}$ A patrimonialização deve se preocupar em não passar a imagem de exotismo e mero entretenimento dos bens culturais protegidos. Segundo José Jorge de Carvalho (2004, p. 8) o entretenimento é um dos pilares da forma urbana capitalista de viver, significando deter o tempo, suspender o "ter" para sonhar com o "ser", ou melhor, sonhar que se "é" (porque se "tem") aquele "ser" que o outro "é": entreter seria fazer um parêntese entre as atividades de trabalho que exigem atenção concentrada e que desgastam a utopia da vida, enquanto se faz uma pausa, assiste-se a um show de duas horas e, em seguida, regressa-se à vida de antes (CARVALHO, 2004, p. 8).
} 
https://doi.org/10.20873/uft.2359-0106.2020.v7n2.p1-27

O horizonte global de modelos ready-made de identidade substitui a produção cara a cara da diferença. Com isso, passou-se a ocupar a posição de um terceiro que disponibiliza a vitrine de identidades prontas para a identificação. Este é o mundo do multiculturalismo anódino e estagnado onde parece suficiente, aos efeitos da identificação, traçar uma equivalência entre o sujeito e um dos itens expostos na galeria global: o negro, o hispânico, o índio, a mulher, o gay, etc., num elenco de essencialismos caricatos. Daí o efeito de enlatamento, a aparência estereotipada das identidades políticas, preparadas eficientemente para o reclamo de recursos e direitos num mundo formatado pela influência avassaladora da formação nacional de identidades do país imperial (SEGATO, 2005, p. 8).

Para reivindicar seus direitos, não necessitam as comunidades quilombolas "enlatar" suas identidades, pois a Constituição já garantiu as suas diversidades e as desvinculou de quaisquer essencialismos históricos e identitários, ao estabelecer que a sua ligação com o passado é "remanescente" (PEREIRA, 2019; 2020). Todavia, o sentido constitucional de remanescência não tem relação com "sobra", com um "passado perdido", tratando-se de reconhecimento de um "passado/presente", no sentido de que tais comunidades resistem às formas opressivas que tentam deslegitimar as suas contemporaneidades e trajetórias, as quais não necessitam estar "frigorificadas" ou "enlatadas", bastando que se auto reconheçam como quilombolas.

Neste ponto, o tombamento do Terreiro da Casa Branca faz-se paradigmático ${ }^{15}$. Demonstrou-se, com ele, que um instituto jurídico de proteção cultural é modelável, desde que para ampliar direitos, às novas necessidades sociais, sendo possível romper com as lógicas racistas e embranquecidas de patrimônio, aproximando-se as políticas públicas patrimoniais das manifestações culturais brasileiras que eram renegadas pelas práticas patrimoniais higienizadas.

${ }^{15}$ Há análises que tocam as questões jurídicas centrais enfrentadas no tombamento do Terreiro Casa Branca, cf. FERREIRA, Maria Ines Caetano; SANTOS, Walkyria Chagas da Silva. Deixa a gira girar: proteção e preservação do patrimônio cultural das religiões afro-brasileiras. Revista de Políticas Públicas, vol. 22, no 1, p. 63-86, jan./jun. 2018; LIMA, Alessandra Rodrigues. Patrimônio cultural afrobrasileiro: narrativas pelo IPHAN a partir da ação patrimonial. Dissertação, Mestrado Profissional do IPHAN, 2012, 157 f.; SERRA, Ordep. Monumentos negros: uma experiência. Afro-Ásia, no 33, p. 169205, 2005; VELHO, Gilberto. Patrimônio, negociação e conflito. Mana: estudos de Antropologia Social, vol. 12, no. 01, p. 237-248, abril, 2006. 
O instituto do tombamento brasileiro, sempre que for invocado para ampliar ou reconhecer direitos culturais de grupos subalternizados, pode, portanto, perder o seu viés engessante, abrindo-se aos diálogos, mostrando-se empático a mudanças, em uma sociedade em que a complexificação exige repensar os paradigmas. O estímulo normativo à escuta da sociedade contrasta com um papel centralista, quando não esclarecedor, do IPHAN e de seus agentes, que tradicionalmente se postam no dever de apontar a importância dos legados patrimoniais aos cidadãos tidos como ignorantes ou agressores de seus legados culturais (MARINS, 2016, p. 17), sendo um aspecto destacável no contexto brasileiro o fato de os intelectuais que se dedicaram ao patrimônio estarem situados no aparelho de Estado ${ }^{16}$, o qual desempenhava um papel central na construção de uma identidade brasileira. No plano institucional, o Estado nacional, durante décadas, operou com certa exclusividade na elaboração e implementação das políticas de patrimônio (GONÇALVES, 2015, p. 219).

\section{PATRIMONIALIZAÇÃO ANTIRRACISTA E O RECONHECIMENTO DE PATRIMÔNIOS INSURGENTES}

O tombamento do Terreiro Casa Branca, em 1986, constituiu o primeiro caso de patrimonialização antirracista (PEREIRA, 2019; 2020). A partir dele, possibilitou-se a entrada da noção e da prática de patrimonialidade negras no campo de proteção estatal, constituindo-se, também, uma vitória contra o racismo, pois se reconheceu a importância da História, dos valores, das criações culturais afro-brasileiras e representou o início de uma política afirmativa de inegável justiça (SERRA, 2005, p. 204).

\footnotetext{
${ }^{16}$ Há obras essenciais para a compreensão desse processo de formação do campo patrimonial no Brasil, cf. CAVALCANTI, Lauro. Modernistas na repartição. Rio de Janeiro: EDUFRJ/IPHAN, 2000; CHUVA, Márcia Regina R. Os arquitetos da memória: sociogênese das práticas de preservação do patrimônio cultural no Brasil (anos 1930-1940). Rio de Janeiro: EDUFRJ, 2009; FONSECA, Maria Cecília L. O patrimônio em processo: trajetória da política federal de preservação no Brasil. Rio de Janeiro: EDUFRJ/IPHAN, 1997; VELOSO, Mariza. O tecido do tempo: o patrimônio cultural no Brasil e a Academia SPHAN, a relação entre o moderno e o barroco. Brasília: EDUnB, 2017.
} 
No mesmo ano, o Conselho Consultivo do IPHAN, igualmente, tombou a Serra da Barriga (o Quilombo dos Palmares), maior símbolo de resistência à escravidão; as proteções ocorreram às vésperas das comemorações do primeiro centenário da Abolição (1988) e passaram a reconhecer o protagonismo de origem africana no rol dos bens preservados, sobejamente ignoradas nos reinados de Rodrigo Melo Franco e de Lúcio Costa por não serem consideradas parte da matriz do ethos nacional, indo além da sobrevalorização das heranças lusitanas (MARINS, 2016, p. 12). Desse modo, foi considerada uma vitória dos afro-brasileiros, festejada por pessoas de diferentes origens, muitas delas sem quaisquer ligações com o candomblé, com intenso apoio da opinião pública, mas, por outro lado, igualmente, com muitos opositores (SERRA, 2005, p. 195).

Não se pode ignorar que o patrimônio nacional forja-se por meio da sua proteção jurídica, que segue rito processual pelo Conselho Consultivo ${ }^{17}$, cuja função, aparentemente, confere-Ihe aspectos de democratização. No entanto, como espaço político e não meramente técnico, as opções políticas patrimoniais passam a receber proteção jurídica sob o discurso da técnica, da isenção, das escolhas patrimoniais. Assim, apesar do processo de tombamento da Casa Branca ter enfrentado resistências intensas no início, criou um precedente poderoso e constituiu um avanço em termos de concepção do patrimônio cultural do Brasil (SERRA, 2005, p. 94).

Essa mudança de paradigma foi consequência de vários fatores, tais como a alteração da perspectiva política a partir dos últimos anos do regime militar, do esgotamento do modelo ideológico adotado pelo órgão encarregado da proteção do patrimônio desde a sua criação e, naturalmente, da atuação da sociedade civil, que se reorganizou em torno de um projeto de redemocratização inclusiva a partir do final dos anos 1970, destacando-se, no campo de matriz africana, a criação do Movimento Negro

17 São interessantes os processos de negociação que ocorrem no Conselho Consultivo do IPHAN, cf. CHUVA, Márcia R. R. Os arquitetos da memória: sociogênese das práticas de preservação do patrimônio cultural no Brasil (anos 1930-1940). Rio de Janeiro: EDUFRJ, 2009, p. 221-227; FONSECA, Maria Cecília L. O patrimônio em processo: trajetória da política federal de preservação no Brasil. Rio de Janeiro: EDUFRJ/IPHAN, 1997, p. 129-134; SOPHIA, Daniela C.; SALDANHA, Mayla R. A invenção do patrimônio: o papel do Conselho Consultivo do IPHAN (1990-2009). Revista Museologia e Patrimônio, vol. 6, no 02, p. 109-125, 2013. 
Unificado - MNU, em 1979, que iria exercer um protagonismo político e pautar as lutas contra o racismo e pela reparação em todo o processo de redemocratização e nos debates da Constituinte (GURAN, 2017, p. 217).

Como se observa, o tombamento da Casa Branca impôs novos parâmetros à política de proteção e preservação do IPHAN, expandindo o conceito de patrimônio, que seria ainda mais alargado pela Constituição de 1988, ao reconhecer bens imateriais como patrimônio e estender a eles a proteção do Estado, em reconhecimento fundamental para garantir a cultura afro-brasileira um protagonismo condizente com seu papel histórico na formação do país (GURAN, 2017, p. 221).

Nota-se que, decorridas algumas décadas após o tombamento do Terreiro Casa Branca, a comunidade do terreiro não entrou sequer uma vez em conflito com as normas de preservação. Não se teve nenhum elemento desse ilê axé alterado e todas as intervenções restauradoras foram apreciadas e aprovadas pelo IPHAN (SERRA, 2005 , p. 199), demonstrando-se que a inadequação do tombamento, levantada pelos seus opositores, em verdade, era racismo institucional e cultural que se valia do instituto jurídico do tombamento para negar direitos às comunidades afrodescendentes, produzindo "não decisão".

A mudança paradigmática promovida no processo de tombamento do Terreiro da Casa Branca permitiu à Constituição Federal ampliar a noção de patrimonialidade brasileira e, em momento posterior, no plano infraconstitucional, a regulamentação do patrimônio imaterial ${ }^{18}$, protagonicamente encabeçada pelas culturas indígenas e afrobrasileiras, como um contraponto ao patrimônio material. Sem embargo, ressalta-se que o avanço estatal concernente ao reconhecimento dessa patrimonialidade ainda é essencialista. Às vezes, advindo dessa noção, apresenta-se o Candomblé como imagem ideal da África e restrito à Bahia, quando, em verdade, há outras religiões afrobrasileiras e o próprio Candomblé há muito tempo se difundiu pelo país, podendo ser

18 A respeito do patrimônio imaterial, cf. CABRAL, Clara Bertrand. Património cultural imaterial: convenção da UNESCO e seus contextos. Lisboa: Edições 70, 2011; SANTACANA MESTRE, Joan; LLONCH MOLINA, Nayra (eds.). El patrimonio cultural inmaterial y su didáctica. Gijón: Ediciones Trea, 2015. 
considerado uma religião de caráter nacional, mas que o racismo religioso ${ }^{19}$ não permite reconhecer esse caráter nacional. Sobre disso, Paulo César G. Marins (2016, p. 24) lembra que,

O Candomblé passou, então, a desempenhar um papel de representação da negritude, mas sem que ele possa ser um efetivo caudal de síntese identitária capaz de identificar o Brasil ou possa concorrer, nesse papel, com o catolicismo, tido oficialmente como a religião emblemática do país e capaz de agregar nossas diferenças. Religiões sínteses como a Umbanda, em que elementos europeus se justapõem a práticas de origem africana, não são prestigiadas pelo tombamento federal, criando assim uma hierarquia fortemente exclusiva entre os cultos afro-brasileiros, em que o Candomblé, obviamente também plástico e sincrético, é isolado e congelado sob a redoma de uma africanidade idealizada (MARINS, 2016, p. 24).

Nesse sentido, percebe-se que o reconhecimento da patrimonialidade negra ainda tem limites condizentes com interesses do próprio Estado, que se vale desse reconhecimento como álibi para não ampliar outros direitos, não reconhecendo a patrimonialidade de outras religiões de matriz afro-brasileira, principalmente aquelas sincretizadas $^{20}$, assim como omitindo a ampla difusão do Candomblé em todos os Estados do país, o que lhe dá status de religião de caráter nacional, superando a deturpada imagem de religião exótica ou folclórica limitada à determinadas regiões do país.

\section{NOVAS POSSIBILIDADES INTERPRETATIVAS A RESPEITO DO TOMBAMENTO A PARTIR DA CONSTITUIÇÃO DE 1988}

19 Sobre racismo religioso, cf. NEVES, Nailah Veleci. Cadê Oxum no espelho constitucional? Os obstáculos sócio-político-culturais para o combate às violações dos direitos dos povos e comunidades tradicionais de terreiro. Dissertação (Mestrado em Direitos Humanos e Cidadania), UnB, 2017, 145 f.; OLIVEIRA, Ariadne Moreira Basílio de. Religiões afro-brasileiras e o racismo: contribuição para a categorização do racismo religioso. Dissertação (Mestrado em Direitos Humanos e Cidadania), UnB, 2017, 104 f.; RAMOS, Luciana de Souza. O direito achado na encruza: territórios de luta, (re) construção da justiça e reconhecimento de uma epistemologia jurídica afro-diaspórica. Tese (Doutorado em Direito), UnB, 2019, 422 f.

20 Sobre o sincretismo, cf. FERRETTI, Sérgio Figueiredo. Repensando o sincretismo. São Paulo: EDUSP - Arché Editora, 2013. A Umbanda, por exemplo, registrada, no Livro de Registro das Atividades e Celebrações, como Patrimônio Cultural de Natureza Imaterial da Cidade do Rio de Janeiro, pelo Decreto Municipal no 42557/2016, já teve inclusive o seu caráter religioso questionado por decisão judicial (BRASIL, 2014). 
Não obstante a promulgação do Decreto $n^{\circ} 3.551$, de 04 de agosto de 2000, que criou o Registro de bens culturais imateriais e o Programa Nacional do Patrimônio Imaterial, o tombamento ainda permanece como o principal instrumento de proteção, sendo mesmo incorporado oficialmente ao Estatuto da Cidade como instrumento de política urbana, apesar de suas conhecidas limitações nesse sentido (SANT'ANNA, 2015, p. 31). Referido decreto, o qual correspondeu como uma resposta à palidez dos tombamentos dos anos 1990, numericamente pouco consideráveis e conceitual ou metodologicamente sem muita renovação, foi uma das bandeiras patrimoniais da era Fernando Henrique Cardoso, sendo inclusive antecessor da criação da nominação internacional do patrimônio imaterial pela UNESCO, por meio da convenção assinada em 2003 e ratificada pelo Brasil em 2006 (MARINS, 2016, p. 16). Veja-se o conteúdo do dispositivo normativo:

Art. 1ํ Fica instituído o Registro de Bens Culturais de Natureza Imaterial que constituem patrimônio cultural brasileiro.

$\S 1$ 1 Esse registro se fará em um dos seguintes livros:

I - Livro de Registro dos Saberes, onde serão inscritos conhecimentos e modos de fazer enraizados no cotidiano das comunidades;

II - Livro de Registro das Celebrações, onde serão inscritos rituais e festas que marcam a vivência coletiva do trabalho, da religiosidade, do entretenimento e de outras práticas da vida social;

III - Livro de Registro das Formas de Expressão, onde serão inscritas manifestações literárias, musicais, plásticas, cênicas e lúdicas;

IV - Livro de Registro dos Lugares, onde serão inscritos mercados, feiras, santuários, praças e demais espaços onde se concentram e reproduzem práticas culturais coletivas.

$\S 2^{\circ}$ A inscrição num dos livros de registro terá sempre como referência a continuidade histórica do bem e sua relevância nacional para a memória, a identidade e a formação da sociedade brasileira.

Após a promulgação do Decreto № 3.551/2000, tem-se a impressão de que se estabeleceu uma espécie de binarismo entre materialidade e imaterialidade. Há críticas no sentido de que essa divisão é, conceitualmente, enganosa, posto que qualquer intervenção na materialidade de um bem cultural provocará modificações na sua 
imaterialidade, e, por outro lado, tal divisão artificial implica em uma política institucional que promove uma distribuição desigual de recursos (CHUVA, 2012b, p. 162).

Como forma de reconhecimento, o registro pode contribuir para a continuidade do bem cultural, já que incentiva a produção de conhecimento e a realização de ações que colaborem para o desenvolvimento sustentável das comunidades e das condições de produção desses bens (LIMA, 2014, p. 7). Em termos jurídicos, deixou-se para o registro do patrimônio imaterial a tarefa de olhar o frágil, o rústico, o improvisado e o instável, características opostas às noções de ancianidade (antiguidade), monumentalidade e originalidade que sempre pautaram o IPHAN (MARINS, 2016, p. 16) e que se valiam do tombamento como único instrumento apto a protegê-las. Todavia, especialistas na temática não deixam de tecer críticas ao instrumento:

Sendo assim, pensar apenas que o Decreto $n^{\circ} 3.551 / 2000$ repara um erro histórico não resolve o problema conceitual dos patrimônios culturais brasileiros. Percebo uma armadilha conceitual da qual os idealizadores do Decreto não conseguiram escapar. Em seu artigo primeiro, parágrafo segundo, o texto jurídico diz: "A inscrição num dos livros de registro terá sempre como referência a continuidade histórica do bem e sua 'relevância' nacional para a memória, a identidade e a formação da sociedade brasileira". Ora, nota-se que a palavra "relevância" está para o Decreto do Imaterial como a palavra "excepcional" está para o Decreto do Tombamento. Ambos são seletivos, excludentes. A representatividade, como advoga Márcia Santana, numa palestra realizada em Goiânia em setembro de 2008, não me parece resolver o problema da relevância. Representar quem? O Brasil? A região? O local? A complexa rede de saberes espalhadas pelo território brasileiro seria representada por um instrumento de indexação nacional? (LIMA FILHO, 2009, p. 622).

Como a sociedade brasileira, em sua formação, caracteriza-se pela tendência de negligenciar sua memória cultural em seus mais diversos aspectos, de forma semelhante, constata-se acentuado descaso do brasileiro na definição dos papéis e relações vivenciados pelos povos responsáveis pela construção da nossa identidade como Nação inserida num processo histórico; de modo tradicional, por meio de imposição brutal por parte do colonizador, perpetuaram-se valores oriundos do europeu, os quais, num esforço constante, sistematicamente excluíram, hierarquizaram 
ou minimizaram a contribuição das outras culturas envolvidas nesse processo (CARNEIRO, 2001, p. 1), como indígenas e afro-brasileiros.

\section{CONCLUSÕES}

Embora atualmente se tenha assumido parcialmente que o Brasil é uma sociedade pluriétnica, detentora de saberes e conhecimentos oriundos da memória coletiva dos nossos diferentes estratos étnicos e sociais, a atuação oficial na tentativa de rememoração ou de preservação dos diferentes suportes de memória tem se caracterizado pela valorização dos testemunhos simbólicos, escritos ou pela preservação dos testemunhos materiais de maior percepção; assim, a política oficial de preservação preocupou-se, num primeiro momento, em valorizar e perpetuar o patrimônio cultural intelectual, material e edificado oriundo das elites, legítimo, mas não o único testemunho da trajetória da nossa sociedade que, na sua gênese, amalgamouse a partir das inter-relações estabelecidas entre os seus diferentes atores sociais (CARNEIRO, 2001, p. 1).

Dessa forma, não há que se contentar apenas com exceções pontuais de patrimonialidade indígena ou negra, havendo constante necessidade de se alcançar amplo reconhecimento de novos patrimônios, como o recente reconhecimento do Cais do Valongo, em seu processo de "redescoberta".

O campo do patrimônio, ao atuar no simbólico e na representação da Nação, manifesta-se como oportunidade para se fomentar fissuras. Pouco estudado por nós juristas, este campo é bastante promissor nos demais ramos das Ciências Sociais. Contudo, o processo de luta é anterior a 1988, como demonstra o tombamento do Terreiro Casa Branca e da Serra da Barriga (Palmares).

O processo de luta contribuiu para o desocultamento da resistência negra, remodelando a patrimonialidade brasileira. As lutas demonstram que os fatores raciais 
são levados em conta nas disputas patrimoniais alcançadas pelo Direito. A partir disso, resulta a necessidade de inserção dessa resistência afro-brasileira no campo de proteção patrimonial, mesmo quando há um discurso informando que os instrumentos jurídicos existentes não alcançam ou não são adequados para proteger esses "novos" patrimônios.

A entrada, na agenda burocrática, desses "novos" patrimônios está ligada diretamente à participação de determinados setores da sociedade civil, notadamente, um campo intelectual e, principalmente, do próprio movimento negro, pressionando a burocracia patrimonial para que abra a sua agenda e tome decisões, sem perder de vista que a questão da memória é um campo de disputas, que os diferentes grupos sociais possuem interesses nem sempre convergentes e que alguns desses grupos detém mais poder de fala do que "os outros".

Nesse contexto, o Direito, como sistema de regulação patrimonial, se abre ou se fecha, conforme as demandas administrativas que the são apresentadas. Caso não haja demandas da sociedade civil, a burocracia dá como resposta, para a sua "não decisão", a informação de que o Direito não regulamenta ou não alcança os "novos" patrimônios.

Por outro lado, caso haja cobrança, a resposta estatal é de abertura da agenda, sempre de modo comedido, adequando o uso do Direito a tais demandas, como evidenciam os processos de tombamento do Terreiro Casa Branca, Serra da Barriga (Quilombo dos Palmares) e Quilombo do Ambrósio. Portanto, o problema é muito menos de inadequação do Direito, ou do instituto do tombamento, tratado neste artigo, e muito mais de disposição para se usar ou não o mesmo para a formação de agenda e de seus usos administrativos.

\section{REFERÊNCIAIS}

BRASIL. Tribunal Regional Federal da $2^{\underline{a}}$ Região. 17 $7^{\text {a }}$ Vara Federal da Seção Judiciária do Rio de Janeiro. Decisão no processo sob os autos de no 0004747-33.2014.4.02.5101 0004747-33.2014.4.02.5101, Rio de Janeiro, 28/04/2014, p. 153-155. 
BRAGA, Robério dos Santos Pereira. O instituto do tombamento e proteção do bem cultural. Manaus: UEA Edições, 2007.

BRITO, Miguel Nogueira de. O procedimento de classificação de bens culturais. In: GOMES, Carla Amado; RAMOS, José Luís Bonifácio (orgs.). Direito da cultura e do património cultural. Lisboa: AAFDL (Universidade de Lisboa), 2011, p. 418-436.

CABRAL, Clara Bertrand. Património cultural imaterial: convenção da UNESCO e seus contextos. Lisboa: Edições 70, 2011.

CALABRE, Lia. Políticas culturais no Brasil: dos anos 1930 ao século XXI. Rio de Janeiro: Editora FGV, 2009.

CARNEIRO, Deusdédit. O tombamento da Casa das Minas. Boletim on-line da Comissão Maranhense de Folclore, São Luís, no 18, p. 1-2, jan. 2001.

CARSALADE, Flávio de Lemos. A preservação do patrimônio como construção cultural. Arquitextos, São Paulo, ano 12, no 139.03, p. 1-9, dez. 2011.

CARVALHO, José Jorge de. Metamorfoses das tradições performáticas afro-brasileiras: do patrimônio cultural a indústria de entretenimento. Série Antropologia, Brasília (UnB), no 354, p. 1- 21, 2004.

CAVALCANTI, Lauro (org.). Modernistas na repartição. 2. ed. Rio de Janeiro: Editora UFRJ - IPHAN, 2000.

CAVALCANTI, Maria Laura Viveiros de Castro. A Casa das Minas de São Luís do Maranhão e a saga de Nã Agontimé. Sociologia \& Antropologia, Rio de Janeiro (UFRJ), vol. 9, no 02, p. 387-429, maio/ago. 2019.

CHUVA, Márcia. Os arquitetos da memória: sociogênese das práticas de preservação do patrimônio cultural no Brasil (anos 1930-1940). Rio de Janeiro: Editora UFRJ, 2009.

- Por uma história da noção de patrimônio cultural no Brasil. Revista do Patrimônio Histórico e Artístico Nacional, Brasília (IPHAN), vol. 34 [dossiê História e Patrimônio], p. 147-166, 2012b.

Preservação do patrimônio cultural no Brasil: uma perspectiva histórica, ética e política. In: CHUVA, Márcia R.; NOGUEIRA, Antonio Gilberto Ramos. Patrimônio cultural: políticas e perspectivas de preservação no Brasil. Rio de Janeiro: Mauad FAPERJ, 2012c, p. 67-78.

CHUVA, Márcia; NOGUEIRA, Antonio Gilberto Ramos. Patrimônio cultural: políticas e perspectivas de preservação no Brasil. Rio de Janeiro: Mauad - FAPERJ, 2012c. 
COELHO, Teixeira. A cultura e seu contrário: cultura, arte e política pós-2001. São Paulo: lluminuras/Itaú Cultural, 2008.

COSTA, Everaldo Batista da. Cidades da patrimonizalização global: simultaneidade totalidade urbana - totalidade-mundo. São Paulo: Humanitas/FAPESP, 2015.

COSTA, Rodrigo Vieira. A dimensão constitucional do patrimônio cultural: o tombamento e o registro sob a ótica dos direitos culturais. Rio de Janeiro: Lumen Juris: 2011.

CUNHA FILHO, Francisco Humberto (org.). Proteção do patrimônio cultural brasileiro por meio do tombamento: estudo crítico e comparado das legislações estaduais organizada por regiões. Fortaleza: Edições UFC, 2013.

DURAND, José Carlos. Política cultural e economia da cultura. Cotia/São Paulo: Ateliê Editorial/Edições SESC, 2013.

FEITOZA, Paulo Fernando de Britto. Patrimônio cultural: proteção e responsabilidade objetiva. Manaus: Editora Valer, 2012.

FERREIRA, Maria Ines Caetano; SANTOS, Walkyria Chagas da Silva. Deixa a gira girar: proteção e preservação do patrimônio cultural das religiões afro-brasileiras. Revista de Políticas Públicas, São Luís (UFMA), vol. 22, no 1, p. 63-86, jan./jun. 2018.

FERRETTI, Mundicarmo. Encantaria maranhense: um encontro do negro, do índio e do branco na cultura afro-brasileira. Boletim on-line da Comissão Maranhense de Folclore, São Luís, № 18, p. 7-9, jan. 2001.

FERRETI, Sérgio Figueiredo. Casa das Minas - religião popular e mudança. Revista do Patrimônio Histórico e Artístico Nacional, Brasília (IPHAN), № 25 [negro brasileiro], p. 38-42, 1997.

. Beija-flor e a Casa das Minas. Boletim on-line da Comissão Maranhense de Folclore, São Luís, no 18, p. 9-10, jan. 2001.

Tombamento da Casa das Minas. Boletim on-line da Comissão Maranhense de Folclore, São Luís, № 24, p. 3, dez. 2002.

. Querebentã de Zomadônu: etnografia da Casa das Minas do Maranhão. 3. ed. São Paulo: Pallas, 2009.

2013.

. Repensando o sincretismo. 2. ed. São Paulo: EDUSP -Arché Editora, 
FONSECA, Maria Cecília Londres. O patrimônio em processo: trajetória da política federal de preservação no Brasil. Rio de Janeiro: Editora UFRJ - IPHAN, 1997.

FUNARI, Pedro Paulo Abreu; PELEGRINI, Sandra de Cássia Araújo. Patrimônio histórico e cultural. Rio de Janeiro: Zahar, 2006.

GOMES, Carla Amado. Textos dispersos de direito do património cultural e de direito urbanístico. Lisboa: AAFDL (Universidade de Lisboa), 2008.

GONÇALVES, José Reginaldo Santos. Autenticidade, memória e ideologias nacionais: o problema dos patrimônios culturais. Estudos Históricos, Rio de Janeiro (FGV), vol. 1, ํo 2, p. 264-275, 1988.

O mal-estar no patrimônio: identidade, tempo e destruição. Estudos Históricos, Rio de Janeiro (FGV), vol. 28, n 55, p. 211-228, jan./jun. 2015.

GURAN, Milton. Sobre o longo percurso da matriz africana pelo seu reconhecimento patrimonial como uma condição para a plena cidadania. Revista do Patrimônio Histórico e Artístico Nacional, Brasília (IPHAN), № 35, p. 213-226, 2017.

IPHAN - Instituto do Patrimônio Histórico e Artístico Nacional. Processo no 1.067-T-82. Tombamento do Terreiro da Casa Branca do Engenho Velho, Sociedade São Jorge do Engenho Velho ou llê Axé lyá Nassô Oká, na cidade de Salvador/BA. Brasília: 1982.

Processo no 1.069-T-82. Tombamento da Serra da Barriga (Quilombo dos Palmares), União dos Palmares/AL. Brasília: 1982b.

KUHN, Thomas S. A estrutura das revoluções científicas. Tradução de Beatriz Vianna Boeira e Nelson Boeira. São Paulo: Perspectiva, 1995.

LEAL, João. Religião como cultura? As festas do Divino, o Tambor de Mina e o regime patrimonial. Revista Pós Ciências Sociais, (UFMA), vol. 15, № 30, p. 91-112, jul./dez. 2018.

LIMA, Alessandra Rodrigues. Patrimônio cultural afro-brasileiro: narrativas pelo IPHAN a partir da ação patrimonial. Dissertação apresentada junto ao Programa de Mestrado Profissional do Instituto do Patrimônio Histórico e Artístico Nacional - IPHAN, 2012, $157 \mathrm{fl}$.

. Reconhecimento do Patrimônio Cultural Afro-brasileiro. Revista Palmares: cultura afro-brasileira, Brasília, ano X, edição 08, p. 6-15, nov. 2014.

LIMA FILHO, Manuel Ferreira. Da matéria ao sujeito: inquietação patrimonial brasileira. Revista de Antropologia, São Paulo (USP), vol. 52, no 2, p. 605-632, 2009. 
PEREIRA, Julia Wagner. O tombamento: de instrumento a processo na construção de uma ideia de Nação. In: CHUVA, Márcia; NOGUEIRA, Antonio Gilberto Ramos. Patrimônio cultural: políticas e perspectivas de preservação no Brasil. Rio de Janeiro: Mauad - FAPERJ, 2012c, p. 159-170.

PEREIRA, Nunes. A Casa das Minas: contribuição ao estudo das sobrevivências daomeianas no Brasil. Introdução de Arthur Ramos. Rio de Janeiro: Sociedade Brasileira de Antropologia e Etnologia - SBAE, 1947.

MARCHESAN, Ana Maria Moreira. A tutela do patrimônio cultural sob o enfoque do direito ambiental. Porto Alegre: Livraria do Advogado, 2007.

MARINS, Paulo César Garcez. Novos patrimônios, um novo Brasil? Um balanço das políticas patrimoniais federais após a década de 1980. Estudos Históricos, Rio de Janeiro (FGV), vol. 29, no 57, p. 9-28, jan./abr. 2016.

MARTINS, Clerton (org.). Patrimônio cultural: da memória ao sentido do lugar. São Paulo: Roca, 2006.

MENESES, Ulpiano Toledo Bezerra de. O campo do patrimônio cultural: uma revisão de premissas. Conferência Magna. I Fórum Nacional do Patrimônio Cultural. I vol.1. In: IPHAN. I Fórum Nacional do Patrimônio Cultural: Sistema Nacional de Patrimônio Cultural: desafios, estratégias e experiências para uma nova gestão, Ouro Preto/MG, 2009. Anais, vol.2, tomo 1. Brasília: IPHAN, 2012, p. 25-39.

MOURÃO, Henrique Augusto. Patrimônio cultural como um bem difuso: o direito ambiental e a defesa dos interesses coletivos por organizações não governamentais. Belo Horizonte: Del Rey, 2009.

NEVES, Nailah Veleci. Cadê Oxum no espelho constitucional? Os obstáculos sóciopolítico-culturais para o combate às violações dos direitos dos povos e comunidades tradicionais de terreiro. Dissertação apresentada ao Programa de Pós-Graduação em Direitos Humanos e Cidadania do Centro de Estudos Avançados Multidisciplinares CEAM, Universidade de Brasília - UnB, 2017, 145 fl.

NOGUEIRA, Antonio Gilberto Ramos. Diversidade e sentidos do patrimônio cultural: uma proposta de leitura da trajetória de reconhecimento da cultura afro-brasileira como patrimônio nacional. Anos 90: Programa de Pós-Graduação em História, Porto Alegre (UFRGS), vol. 15, no 27, p. 233-255, jul. 2008.

OLIVEIRA, Ariadne Moreira Basílio de. Religiões afro-brasileiras e o racismo: contribuição para a categorização do racismo religioso. Dissertação apresentada junto ao Programa de Pós-Graduação em Direitos Humanos e Cidadania do Centro de 
Estudos Avançados Multidisciplinares - CEAM, Universidade de Brasília - UnB, 2017, $104 \mathrm{fl}$.

PAULA, Zuleide Casagrande de; MENDONÇA, Lúcia Glicério; ROMANELLO, Jorge Luís (org.). Polifonia do patrimônio. Londrina: EDUEL, 2012.

PEREIRA, Paulo Fernando Soares. O direito ao desenvolvimento cultural e as políticas de proteção ao patrimonio cultural. Rio de Janeiro: Lumen Juris, 2015.

Os esquecimentos da memória: o tombamento do patrimônio cultural quilombola e a formulação de uma política pública. Tese (Doutorado em Direito), Universidade de Brasília - UnB, 2019, 350 f.

. Os Quilombos e a Nação: inclusão constitucional, políticas públicas e antirracismo patrimonial. Rio de Janeiro: Lumen Juris, 2020.

RABELLO, Sonia. O Estado na preservação de bens culturais: o tombamento. Rio de Janeiro: IPHAN, 2009.

RAMOS, Luciana de Souza. O direito achado na encruza: territórios de luta, (re) construção da justiça e reconhecimento de uma epistemologia jurídica afro-diaspórica. Tese apresentada junto ao Programa de Pós-Graduação em Direito, Estado e Constituição, Universidade de Brasília - UnB, 2019.

RODRIGUES, Francisco Luciano Lima. Patrimônio cultural: a propriedade dos bens culturais no Estado Democrático de Direito. Fortaleza: UNIFOR, 2008.

RODRIGUES, José Eduardo Ramos; MIRANDA, Marcos Paulo de Souza. Estudos de direito do patrimônio cultural. Belo Horizonte: Fórum, 2012.

SANT'ANNA, Márcia. Preservação como prática: sujeitos, objetos, concepções e instrumentos. In: REZENDE, Maria Beatriz; GRIECO, Bettina; TEIXEIRA, Luciano; THOMPSON, Analucia (Orgs.). Dicionário IPHAN de Patrimônio Cultural. Rio de Janeiro/Brasília: IPHAN/DAF/CcOPEDOC, 2015.

SANTACANA MESTRE, Joan; LLONCH MOLINA, Nayra (eds.). El patrimonio cultural inmaterial y su didáctica. Gijón: Ediciones Trea, 2015.

SEGATO, Rita Laura. Raça é signo. Série Antropologia, Brasília (UnB), № 372, p. 1 16, 2005.

SERRA, Ordep. Monumentos negros: uma experiência. Afro-Ásia, Salvador (UFBA), no 33, p. 169-205, 2005. 
SILVA, José Afonso da. Ordenação constitucional da cultura. São Paulo: Malheiros, 2001.

SOARES, Inês Virgínia Prado. Direito ao (do) patrimônio cultural brasileiro. Belo Horizonte: Fórum, 2009.

SOPHIA, Daniela Carvalho; SALDANHA, Mayla Ramos. A invenção do patrimônio: o papel do Conselho Consultivo do IPHAN (1990-2009). Revista Museologia e Patrimônio: Programa de Pós-Graduação em Museologia e Patrimônio, (Universidade Federal do Estado do Rio de Janeiro - UNIRIO), vol. 6, noำ 2, p. 109-125, 2013.

VELHO, Gillberto. Patrimônio, negociação e conflito. Mana: estudos de Antropologia Social, Rio de Janeiro (Museu Nacional/UFRJ), vol. 12, no. 01, p. 237-248, abril 2006.

VELOSO, Mariza. O tecido do tempo: o patrimônio cultural no Brasil e a Academia SPHAN, a relação entre o moderno e o barroco. Brasília: Editora UnB, 2018.

VERGER, Pierre. Uma rainha africana mãe de santo em São Luís. Revista USP, São Paulo, p. 152-158, jun./ago. 1990.

ZANDONADE, Adriana. O tombamento à luz da Constituição Federal de 1988. São Paulo: Malheiros, 2012. 